\title{
Reuna
}

\section{CRITÉRIOS QUE BALIZAM A ESCOLHA DE FRANQUIAS}

\section{CRITERIA FOR THE CHOICE OF FRANCHISES}

http://dx.doi.org/10.21714/2179-8834/2019v24n2p44-66

\author{
Fernando Mynarski Silveira \\ Universidade Federal do Rio Grande do Sul (UFRGS), Brasil. \\ E-mail: fernandomynarski@hotmail.com
}

Submissão: 22 Dez. 2018 Publicação: 15 Out. 2019. Sistema de avaliação: Double blind review. Centro Universitário UNA, Belo Horizonte - MG, Brasil. Editor geral: Prof. Dr. Gustavo Quiroga Souki

Este artigo encontra-se disponível nos seguintes endereços eletrônicos:

http://revistas.una.br/index.php/reuna/article/view/1060

http://dx.doi.org/10.21714/2179-8834/2019v24n2p44-66

\section{Resumo}

Franchising é um assunto presente no mundo dos negócios atualmente. O estudo apresentado neste artigo teve como objetivo principal identificar os fatores que balizam a escolha de franquias por parte de (pretensos) franqueados. Para o alcance desse objetivo, dois tipos de fontes de informação foram investigados: (i) Revisão da literatura e (ii) entrevistas com os próprios (pretensos) franqueados. Ao fim, foi gerada uma estrutura que contemplou trinta e seis fatores balizadores. Esses fatores foram classificados em dimensões, sendo que a dimensão que agregou o maior número de fatores foi "sinalização de valor", tendo a "comunicação" como mediadora. Para cada fator balizador da escolha de franquias, apoiado nos resultados das entrevistas, foi calculado o seu grau de importância médio, bem como foi contabilizado o número de citações indicando o mesmo como de caráter mandatório no processo de escolha de uma franquia. Descobriu-se, por exemplo, que os itens financeiros não são os únicos considerados mais importantes e mandatórios. Os segmentos estudados foram "alimentação", "vestuário", "automotivo", "serviços" e "educação/entretenimento". A praça objeto de entrevista foi Porto Alegre e sua região metropolitana.

Palavras-chave: Franchising; Franqueador; Franqueado; Critérios de seleção. 


\section{Abstract}

Franchising is a business present today. The study presented in this article had as main objective to identify the factors that guide the choice of franchises by (pretenses) franchisees. In order to reach this objective, two types of information sources were investigated: (i) Review of the literature and (ii) interviews with the (alleged) franchisees themselves. At the end, a structure was generated that contemplated thirty-six buoyant factors. These factors were classified into dimensions, and the dimension that added the greatest number of factors was "signaling value", with "communication" as a mediator. Based on the results of the interviews, the average degree of importance was calculated for each factor determining the franchise choice, as well as the number of citations indicating the same as mandatory in the process of choosing a franchise. It turned out, for example, that financial items are not the only ones considered more important and mandatory. The segments studied were "food", "clothing", "automotive", "services" and "education / entertainment". The square object of interview was Porto Alegre and its metropolitan region.

Keywords: Franchising; Franqueador; Franqueado; Critérios de seleção.

\section{Introdução}

A globalização, o aumento da competitividade empresarial e as constantes mudanças geram desafios e oportunidades no mercado de trabalho. $O$ empreendedorismo surge como uma das alternativas de (re)colocação profissional nesse ambiente, em detrimento, por exemplo, da busca pelo emprego. Entretanto, o empreendedorismo tem como um dos requisitos principais que o empreendedor se adeque a certo perfil. Além da necessidade de dispor de recursos para investir, precisa também ter baixa aversão ao risco. O Franchising insere-se como uma alternativa de empreendedorismo. Desde a década de 1990, artigos acadêmicos já faziam menção ao Franchising no contexto citado anteriormente: mudanças no ambiente econômico global, como a redução das barreiras comerciais, aumento da integração através das fronteiras nacionais e uma maior homogeneização no comportamento do consumidor apresentam um novo mercado de oportunidades para o Franchising (CHAN e JUSTIS, 1992; QUINN, 1999).

O Franchising é uma das áreas de maior crescimento no mundo dos negócios (BENNETT, 2008; CAMPBELL ET AL. 2009; SZULANSKI e JENSEN, 2008). No Brasil, segundo informações colhidas no sítio eletrônico da Associação Brasileiras de Franchising (2016), o faturamento do Franchising como um todo, o número de franqueadores e franqueados, o número de empregos criados pelo Franchising e o número de marcas aderindo a esse tipo de modelo de negócio cresce a cada ano. Além disso, as projeções para os anos seguintes são otimistas. Isso tende a ter um significado ainda maior, principalmente, levando-se em consideração que, em 2015, o Brasil teve retração do PIB estimada em 3,71\%, segundo o Boletim Focus, divulgado pelo Banco Central (2015). A Lei n 8.955/1994, popularmente conhecida como Lei de Franquias, define Franchising como sendo um sistema pelo qual um franqueador cede ao franqueado o direito de uso de marca ou patente, associado ao direito de distribuição exclusiva ou semi-exclusiva de produtos ou serviços e, 
eventualmente, também ao direito de uso de tecnologia de implantação e administração de negócio ou sistema operacional desenvolvidos ou detidos pelo franqueador, mediante remuneração direta ou indireta, sem que, no entanto, fique caracterizado vínculo empregatício (BRASIL, 1994).

Tradicionalmente, estudos sobre Franchising têm investigado questões como o redirecionamento da propriedade (HUNT, 1973; DANT ET AL. 1992), eficiência (NORTON, 1988; LAFONTAINE, 1992), controle (BRICKLEY e DARK, 1987), coordenação (LAL, 1990) e o fracasso dos novos sistemas de franquias (SHANE, 1998) sob a perspectiva doméstica. Posteriormente, têm-se realizado estudos sob a ótica global (KARUPPUR, 2002). De todo modo, tanto sob a perspectiva doméstica, quanto sob a perspectiva global, há poucos relatos sobre os fatores ou critérios que influenciam pretensos franqueados a optarem por investir em uma franquia ou outra. Esses critérios, segundo o modelo sugerido por Cori Hodge, Harmen Oppewal e Civilai Terawatanavong (2013) sobre conversão de franqueados para outras franquias, são direcionados pelos custos e benefícios relacionados, pela força da marca e pela estimativa do futuro nível de controle exercido pelo franqueador. $O$ modelo também cita que o fato de o franqueado já ter tido um elevado grau de experiência em Franchising é uma das condicionantes que impactam nessa escolha. Peterson e Dant (1990) descobriram que franqueados menos experientes identificam maiores vantagens em Franchising que aqueles mais experientes.

Existem algumas dificuldades enfrentadas pelos pretensos franqueados nessa tomada de decisão. Pode-se citar, por exemplo, o pouco grau de abertura de informações prestadas pela empresa franqueadora sobre a franquia ofertada; 0 desconhecimento de que o financiamento bancário para abertura de uma franquia costuma ter taxas mais baratas; a incapacidade de uma mensuração mais precisa sobre a influência positiva ou negativa do fator localização da unidade a ser aberta, que também está relacionada à questão da concorrência etc. Do mesmo modo, pode-se citar também fatores endógenos, como a maneira de avaliar a aderência do perfil do pretenso franqueado a uma determinada franquia. Tendo em vista o que foi relatado nos parágrafos anteriores, entende-se que é relevante estudar mais profundamente quais são os critérios que impactam na escolha de uma franquia. Assim, o objetivo do presente trabalho é descobrir quais são os fatores que impactam a escolha por uma franquia por parte de um pretenso franqueado, em detrimento de outras franquias. O estudo justifica-se pelo fato de que, sabendo quais são esses fatores, pode-se posteriormente avaliá-los para que o grau de assertividade na adesão a uma determinada franquia seja maximizado.

Este artigo está organizado em cinco seções. Após esta introdução, a segunda seção apresenta uma revisão da literatura abordando quais são os critérios que impactam a escolha por uma determinada franquia. A terceira seção descreve 0 método empregado na identificação dos critérios de escolha. A quarta seção apresenta os resultados obtidos, detalhando a estrutura da decisão e os critérios identificados. Por fim, a quinta seção resume os principais achados de pesquisa e sugere trabalhos futuros. 


\section{Referencial Teórico}

\subsection{Franquias - Visão Geral e Contexto Prático}

Segundo Anwar (2011), as seis principais categorias de franquias predominantes no contexto norte-americano divididas em blocos são: (i) Alimentação/restaurantes; (ii) Produtos e serviços automotivos; (iii) Produtos e serviços para o público infantil; (iv) Manutenção/limpeza; (v) Construção e serviços correlatos de acabamento; (vi) Auxiliares de negócios e serviços. A categoria Alimentação/Restaurantes apresenta o maior faturamento global quando comparado com os das outras categorias. Dentro dessa categoria destacam-se as redes de fast food. Davidovitsch et al. (2009) realizaram um estudo focado nesse tipo de rede no contexto brasileiro. Empiricamente, constataram que tanto os fatores ligados à teoria da escassez de recursos, quanto os fatores ligados à teoria da agência apresentaram efeitos significativos sobre o nível de utilização do Franchising e sobre o desempenho das firmas franqueadoras.

Melo et al. (2013) fizeram um estudo comparativo entre franquias convencionais e microfranquias, também no contexto brasileiro. No estudo, conceituaram microfranquias como sendo aquelas que requeriam à época um investimento de até $R \$ 50.000,00$. Constataram que os franqueados de franquias convencionais tendem a dar maior valor à qualidade da marca quando comparados aos das microfranquias.

Há um grande número de estudos que tratam da questão do relacionamento entre franqueado e franqueador. Altinay et al. (2013), por exemplo, desenvolveram um modelo com a configuração apresentada na Figura 1.

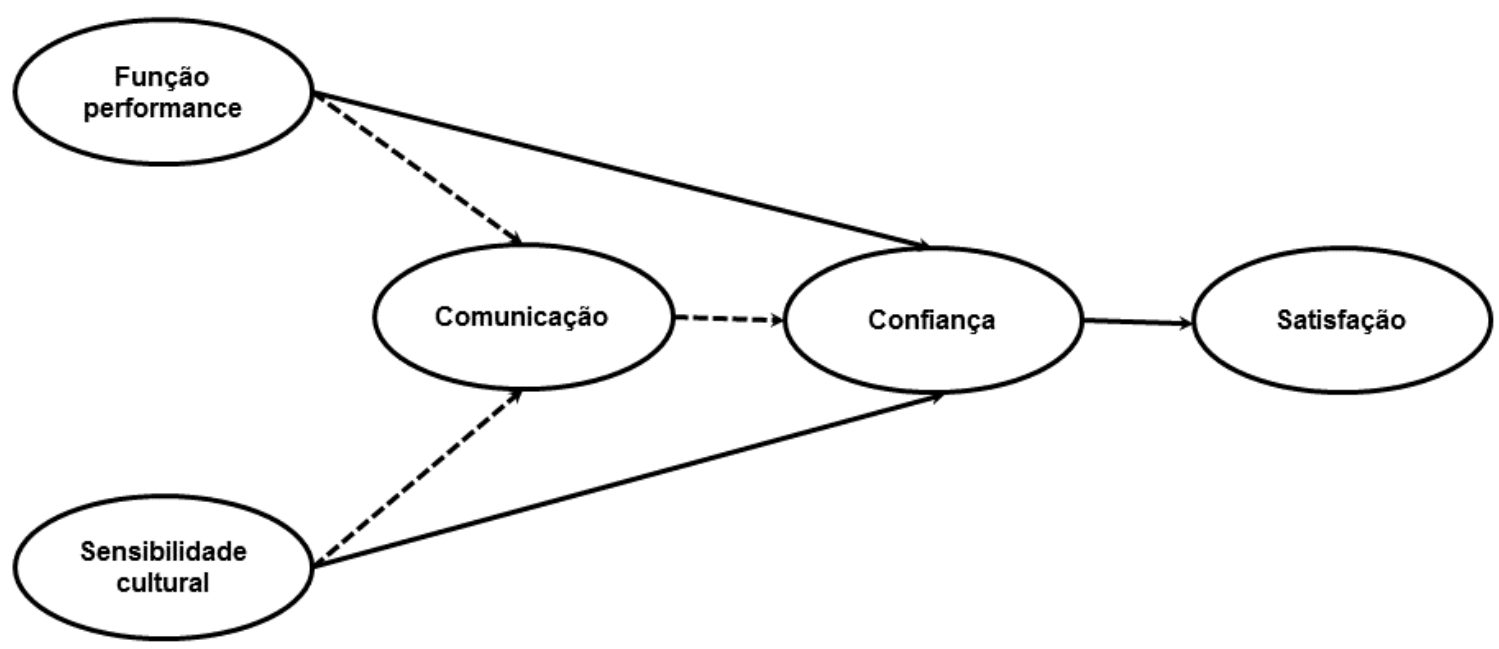

Figura 1 - Modelo conceitual

Fonte: Altinay et al. (2013)

Nesse modelo, entende-se por Função Performance basicamente os treinamentos e suportes operacionais ofertados pelo franqueador, enquanto a Sensibilidade Cultural é dada pelo comportamento consciencioso e sensitivo do franqueador. Esses dois vetores impactam positivamente na confiança do relacionamento. Existe ainda um papel mediador que é o da Comunicação realizada pelo franqueador aos seus franqueados. A Comunicação tem um efeito indireto de RELUNA, Belo Horizonte - MG, Brasil, v.24, n.2, p.44-66, Abr. - Jun. 2019 - ISSN 2179-8834 
mais de $50 \%$ no desenvolvimento da confiança. Por fim, o citado modelo sugere que, quando os franqueados desenvolvem confiança no franqueador, aqueles se tornam mais propensos a expressar satisfação com este.

Diferentemente do modelo proposto anteriormente, Grace et al. (2016), construíram um modelo um pouco mais autoexplicativo, onde os requisitos que geram confiança nos franqueados em relação ao seu franqueador teriam a configuração apresentada na Figura 2.

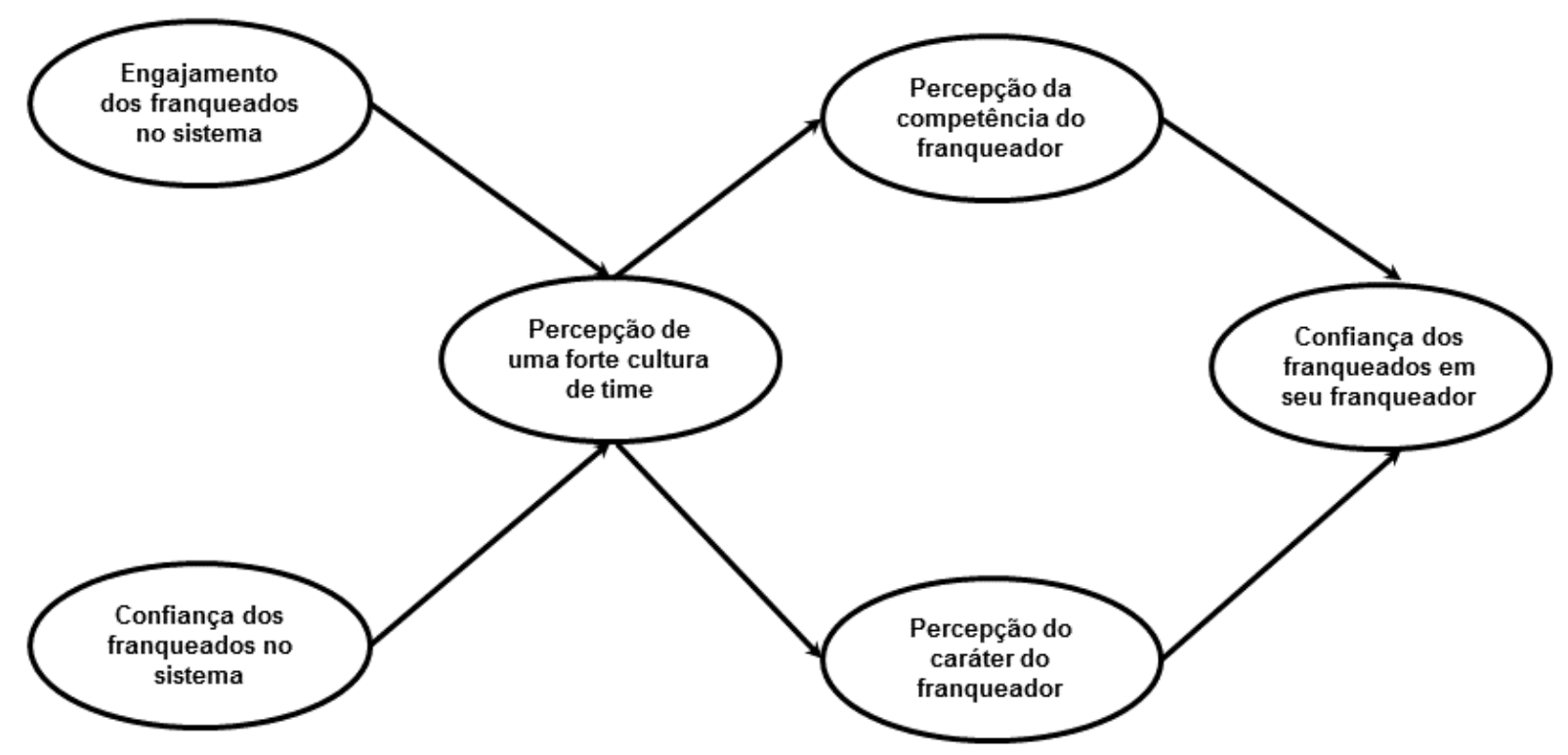

Figura 2 - Modelo de confiança do franqueado

Fonte: Grace et al. (2016)

O engajamento dos franqueados teria correlação positiva com a sua própria força de barganha, bem como com o reconhecimento dado pelo franqueador a eles. Já a confiança dos franqueados no sistema seria catalisada por uma boa comunicação pelo franqueador, informação compatível inclusive com o modelo proposto por Altinay et al. Os principais valores que fortaleceriam a cultura de time são: franqueza, comunicação aberta, camaradagem e integridade. A percepção da competência do franqueador estaria intimamente associada ao suporte técnico prestado pelo mesmo. Por fim, o caráter do franqueador seria percebido fundamentalmente pelo tratamento pessoal dispensado aos franqueados.

Ainda sobre o tema relacionamento franqueado-franqueador, Lee et al. (2015) sugerem que haveria três tipos principais de vínculos relacionais: (i) os estruturais, (ii) os sociais e (iii) os financeiros. Nos três casos, a duração do relacionamento seria um mediador indireto. Quanto à percepção de benefícios pelos franqueados, intuem os autores que os vínculos sociais impactam mais no curto prazo, enquanto os vínculos estruturais impactam mais no estágio final do relacionamento. Mesmo assim, é possível generalizar que os vínculos sociais são mais influentes do que os vínculos estruturais na percepção dos benefícios obtidos, ao passo que os vínculos financeiros não têm impacto significativo na percepção dos mesmos. 
Dant et al. (2011) fizeram um estudo sobre como cada uma das cinco dimensões da personalidade humana propostas por eles afetariam a qualidade do relacionamento franqueado-franqueador, validando a hipótese de que não se pode tratar as franquias de forma a se desconsiderar o lado humano. O resultado gerado apontou quais os principais traços de personalidade do franqueado que afetam positivamente a sua relação com o franqueador: ser agradável, ser consciencioso e ser estável emocionalmente. Constatou-se que ser extrovertido é um aspecto que afeta negativamente. Por fim, ser intelectual/imaginativo não tem influência na relação. Essa análise possibilita avaliar quais franqueados têm mais chances de aderir às propostas dos franqueadores, bem como adicionar valor à rede.

Vance et al. (2008), em um estudo sobre a satisfação do franqueado brasileiro na primeira década do Século XXI, apontam que a satisfação tem relação com o segmento de atuação, mas não está associada ao tempo de operação. No mesmo estudo, apontam que, em média, os franqueados brasileiros não estão contentes com as ações promocionais, com as orientações tributárias, com as ações de marketing, com a gestão de fundo de publicidade e com as orientações gerais sobre gestão provenientes do franqueador. Afirmam ainda que os franqueados não estão contentes com a rentabilidade do segmento em que atuam. Curiosamente, embora haja grande insatisfação quanto a esses diversos fatores, o Franchising continua a crescer no Brasil.

Tal crescimento do Franchising brasileiro no Século XXI resultou inclusive na publicação de um artigo sobre as características comuns dos países onde já existem franquias brasileiras instaladas. Nessa obra, Melo et al. (2015) utilizaram análise de aglomerados para classificar os diversos países em três grandes grupos, levando-se em conta as oportunidades de mercado (OM) e a eficiência de negócios (EN), quais sejam:

- África e grandes países da América Latina - baixas OM e EN;

- Países desenvolvidos (exceto os Estados Unidos da América) e pequenos países da América Latina - baixa OM e alta EN; e;

- Os Estados Unidos da América (EUA) - altas OM e EN.

\subsection{Critérios que balizam a escolha de franquias}

Como visto na seção anterior, o modelo proposto por Altinay et al. (2013) teve a Comunicação proveniente do franqueador como um fator mediador tanto da Função Performance quanto da Sensibilidade Cultural no desenvolvimento da confiança do franqueado e consequente atingimento de sua Satisfação. A Função Performance é representada majoritariamente pelos níveis de suporte do franqueador antes e depois da abertura das unidades franqueadas. Já a Sensibilidade Cultural pode ser vista predominantemente pela capacidade de adaptação do franqueador às especificidades da região onde se situa cada franquia.

Pretensos franqueados deveriam investigar mais profundamente os canais de comunicação e os níveis de suporte dos franqueadores nas fases de pré e pós abertura de franquias. Eles deveriam também buscar evidências da disposição de adaptação dos franqueadores, dado o impacto que essas abordagens têm na satisfação dos franqueados (ALTINAY ET AL., 2013). Com isso, é razoável supor que são critérios que balizam a escolha de franquias os canais de comunicação, os 
níveis de suporte oferecidos pelos franqueadores e a capacidade do franqueador de se adaptar às especificidades regionais de cada franquia.

Já Nyadzayo et. al. (2014) citam que é racional sugerir que, quando se recrutam novos franqueados, é crucial para os franqueadores selecionar aqueles cujos valores estão alinhados com a imagem de sua marca. Assim, olhando-se sob outra ótica, a percepção da marca pelos pretensos franqueados também pode ser um critério importante na escolha de franquia. Além disso, de acordo com o modelo proposto pelos mesmos autores, a percepção da marca é um fator mediador do suporte oferecido pelo franqueador. Logo, além de Altinay et al., Nyadzayo et al. também entendem que o suporte oferecido pelo franqueador a sua rede influencia na adesão de uma nova franquia.

Juste et al. (2014) afirmam que a sinalização de valor de uma rede franqueada ajuda a atrair a adesão de pretensos franqueados. No caso, os franqueadores deveriam cuidar da reputação da marca e da qualidade da rede como um todo. Sobre a qualidade da rede em estudo, os pretensos franqueados valorizam: um melhor treinamento e assistência financeira, as restrições de propriedade passiva da franquia, a proibição de acordos de desenvolvimento de área e o subfranqueamento. Paralelamente, analisam também, mas em segundo plano, a experiência da franquia e o equilíbrio expresso por uma quantidade ótima entre número de negócios próprios do franqueado e número de unidades franqueadas.

De acordo com o trabalho realizado por Weaven et al. (2013), os franqueados, em suas decisões visando desenvolver a confiança junto aos franqueadores, comportam-se de maneira diferente de acordo com o seu sexo. Para franqueados do sexo masculino, o que mais importa é a confirmação das informações anteriormente prestadas pelos franqueadores. Além disso, quanto menos conflitos tiverem com os franqueadores, melhor. Já os franqueados do sexo feminino, o que mais importa é um bom relacionamento com os franqueadores. No caso das mulheres, certa dose de conflito é, inclusive, bem vista. Então é possível afirmar que os critérios utilizados por ambos os sexos podem diferir em menor ou maior grau.

Wright e Winzar (2014), na praça australiana, fizeram um estudo sobre como os franqueadores abrindo ao público (disclosure) os detalhes do sistema de investimento de uma franquia poderiam sinalizar valor para os pretensos franqueados. A pesquisa apresentada surpreendeu, indicando que a combinação de quatro características das franquias estaria situada em um patamar superior ao do próprio preço da franquia (preço este que tem relação com o sistema de investimento). A combinação apontada é a seguinte: o território onde se situa a franquia, a maturidade do sistema, a política de seleção e a experiência do franqueador.

Hodge et al. (2013) fizeram um estudo sobre o que influencia a conversão para determinadas franquias. Os sujeitos ativos dessa conversão seriam negócios independentes ou mesmo franquias de outras marcas. Concluíram que os custos relacionais e a força da marca afetam incondicionalmente a probabilidade de converter, enquanto os benefícios relacionais e o nível de controle também afetam, mas não incondicionalmente. Diferindo de Wright e Winzar (2014), citam que os franqueados são calculistas em relação aos custos na hora de converter. Além 
disso, citam que, quanto mais experientes os franqueados, maior é a probabilidade de conversão.

Wu (2015) estudou as condicionantes que impactam os franqueados tailandeses em se manter na rede, bem como na melhora de sua performance. Embora não dirigido especificamente para pretensos franqueados, esse estudo contribui indiretamente na aferição da qualidade da rede como um todo. A conclusão obtida foi a de que a reputação da marca, o conhecimento compartilhado, a confiança conquistada e uma boa gestão de conflitos afetam positivamente a manutenção dos franqueados à rede, bem como na sua performance financeira. Esse tipo de sinalização de valor, quando tangibilizado, também pode ser considerado um critério balizador na escolha de franquias pelos pretensos franqueados.

Brooks e Altinay (2009) fizeram um estudo sobre a abordagem utilizada para selecionar um parceiro franqueador. Eles dividiram o processo em duas vertentes: os critérios de seleção relacionados à tarefa ("task-related selection criteria") e aqueles relacionados ao parceiro ("partner-related selection criteria"). Quando a abordagem adotada pelo pretenso franqueado é estratégica, os autores citam que ambos os critérios de seleção são estudados em um processo de tomada de decisão sequencial. Neste caso, os riscos são mitigados antes da assinatura do contrato, devido ao embasamento das pesquisas previamente feitas e ao eventual relacionamento satisfatório entre franqueado e franqueador. Por outro lado, quando a abordagem tem cunho oportunista, o processo de tomada de decisão é simultâneo. Neste caso, as investigações sobre os dois critérios de seleção são menores, e o processo costuma ser mais rápido até a assinatura do contrato, o que, em muitos casos, aumenta o risco.

Quatro anos após, Brooks, Altinay e Atkas (2013) desmembraram ainda mais, segundo a realidade do setor de turismo da Turquia, os dois critérios de seleção citados anteriormente:

- Os chamados Task-related selection criteria passaram a incluir: (i) Nome /reputação da marca (acesso a uma base de clientes estabelecida e investimentos necessários em marketing reduzidos, ambos pela força da marca); (ii) Produtos (de qualidade, oportunos para o mercado, inovativos e composto por uma linha extensa); e (iii) Suporte do Franqueador (treinamento oferecido, serviços de operação e marketing na abertura e pós abertura da franquia e gestão da cadeia de suprimentos).

- Paralelamente, os chamados Partner-related selection criteria foram desdobrados em: (i) Confiança (que deve ser construída entre pretensos franqueados e franqueadores); e (ii) Confiabilidade dos franqueadores (que deve ser acessada pelos franqueados).

\section{Metodologia de pesquisa}

Esta seção está organizada em duas subseções que abordam: (i) Caracterização da pesquisa; e; (ii) Etapas da pesquisa. 


\subsection{Caracterização da pesquisa}

A presente pesquisa pode ser classificada sob quatro ópticas diferentes. De acordo com a sua natureza, a pesquisa é tida como aplicada, pois gera conhecimentos dirigidos à solução de um problema específico, no caso os fatores que influenciam a escolha de franquias. Já em relação a sua abordagem, trata-se de pesquisa qualitativa, por lidar com análise de textos, depoimentos, comparações e abordagens não numéricas. No caso desta pesquisa, a base qualitativa envolve a opinião de franqueados ou pretensos franqueados em relação aos fatores que influenciam a escolha de franquias. Quanto aos seus objetivos, classifica-se como pesquisa exploratória, porque visa proporcionar maior familiaridade com o problema com vistas a torná-lo mais explícito. Por fim, quanto aos seus procedimentos, a classificação adotada é a qualitative survey. Boyatizis (1998) propõe uma definição formal de qualitative survey, que inclui todos os estudos de diversidade de uma população, sem restrições quanto ao número de ciclos empíricos ou o modo de geração de códigos: data-driven, prior-research-driven ou theory-driven. Groves et al. (2004) definem survey como um método sistemático de compilação de informações de (uma amostra de) entidades com o propósito de construção de descritores quantitativos dos atributos da população das quais as entidades são membras. O ponto é que não são observadas as interações das unidades da população objeto de estudo, apenas as características dos membros individuais envolvidos. Sobre o modo qualitative de definição e investigação da variação de uma população, essa não objetiva estabelecer frequências, médias ou outros parâmetros, mas a determinação da diversidade de alguns tópicos de interesse dentro de uma dada população. Em resumo, qualitative survey é o estudo da diversidade de uma população e não de sua distribuição. Ela explora principalmente significados e experiências.

\subsection{Etapas da pesquisa}

A pesquisa está organizada em quatro etapas, compreendendo: (i) Revisão da literatura e extração dos fatores que impactam a escolha por uma franquia; (ii) Entrevistas com franqueados ou potenciais franqueados investigando fatores que foram (estão sendo) considerados na escolha de uma franquia e extração de outros fatores que impactam a escolha por uma franquia; (iii) Compilação em uma estrutura única dos fatores que impactam a escolha por uma franquia, considerando as contribuições da literatura e de franqueados/potenciais franqueados; e; (iv) Determinação da importância dos fatores e da natureza (compensatório/mandatório) dos mesmos.

Primeiramente fez-se necessário uma leitura aprofundada do Referencial Teórico (Seção 2) do presente artigo. Com tal leitura, foi possível, primeiramente, situar-se sobre o tema franquias de modo genérico. Em um segundo momento, percebeu-se que, através da análise do Referencial Teórico, existem alguns fatores consensuais que balizam a escolha de uma franquia por parte de um pretenso franqueado. Assim, foi possível extrair da literatura os fatores que influenciam a escolha de franquias.

A segunda etapa da pesquisa foi de cunho prático. Procurou-se entrevistar dezoito (pretensos) franqueados de cinco diferentes segmentos de atuação. Dos dezoito entrevistados, nove já eram franqueados, ao passo que os outros nove eram 
ainda pretensos franqueados. Os segmentos escolhidos foram: (i) Alimentação; (ii) Vestuário; (iii) Automotivo; (iv) Serviços; e (v) Educação/Entretenimento. Esses são segmentos típicos que operam sob o sistema de franchising no contexto brasileiro. Alguns desses potenciais franqueados trabalham ou indicaram pretensão em trabalhar em mais de um segmento. Com isso, conseguiu-se que cada um dos segmentos tivesse a indicação de pelo menos 4 potenciais franqueados.

O objetivo da execução das entrevistas foi fazer um levantamento para posteriormente descobrir quais são os fatores que, na prática, são relevantes na escolha de uma franquia para sua adesão. Para tanto, foi construído um questionário abrangendo tanto perguntas fechadas quanto abertas. Tal questionário naturalmente teve alguma influência em sua composição do Referencial Teórico do presente artigo. O cenário escolhido foi a cidade de Porto Alegre e região metropolitana, localizada no sul do Brasil. Entendeu-se que essa localidade é representativa por comportar um mercado relativamente maduro e diversificado. Esse período coincidiu com uma das épocas de crise política e econômica que o país passou recentemente.

Assim como ocorreu na primeira etapa da pesquisa, a segunda etapa foi concluída através da extração dos fatores que impactam a escolha por uma franquia, mas agora realizada diretamente a partir das entrevistas realizadas. Tal extração se deu de maneira mais fácil, pois os questionários das entrevistas foram direcionados para prover tal informação.

A terceira etapa da presente pesquisa tratou de compilar os resultados obtidos na primeira e na segunda etapas. Isso quer dizer que tanto os fatores balizadores da atratividade de uma franquia extraídos da literatura, quanto aqueles obtidos através das entrevistas, foram organizados em uma estrutura única, eliminando-se as eventuais duplicidades. A combinação dessas fontes (teórica e prática) contribui para validar a estrutura apresentada através da compilação dos fatores.

$\mathrm{Na}$ quarta e última etapa desta pesquisa, foi realizado um estudo sobre o encadeamento lógico dos itens da estrutura apresentada na terceira etapa. Para tanto, foi feito um agrupamento por afinidade dos fatores em dimensões. A tônica foi estabelecer uma estrutura de relacionamento dos fatores que impactam a escolha por uma franquia. Foram definidos graus de importância para cada fator, além de classificá-los por sua natureza entre compensatórios ou mandatórios. Para o estabelecimento dos graus de importância dos fatores e sua classificação, a fonte utilizada foi apenas a de cunho prático, obtida pelas entrevistas detalhadas na segunda etapa, onde os graus de importância foram capturados pela perguntamodelo de número cinco e a classificações foram capturadas pela pergunta-modelo de número seis. Como premissa utilizada, considerou-se que a literatura não tem a capacidade de capturar adequadamente o entendimento dos pretensos franqueados sobre franchising no contexto da cultura brasileira, mais especificamente da cultura portoalegrense. Como resultado obteve-se uma estrutura de fatores que facilita o entendimento dos aspectos importantes que envolvem o tema. Tal estrutura é capaz de responder perguntas do tipo: Quais fatores apresentam maior impacto na escolha por uma franquia? Quais os que impactam menos? Quais são mandatórios? Quais são compensatórios? Como os fatores se relacionam entre si qualitativamente? Ao fim, foi feito o cálculo final dos valores médios dos graus de importância e das 
citações de mandatoriedade (classificação) por fator balizador de franquias, que foram calculados da seguinte forma:

$$
\begin{aligned}
\text { Grau de Importância } i & =\frac{(\text { média das notas de relevância } i)}{3} \\
\text { Citações de } M i & =\frac{\text { número de indicações } M i}{18}
\end{aligned}
$$

Onde i refere-se aos fatores, sendo que calculou-se a média das notas de relevância por fator mensurando-se cada resposta dada nas entrevistas da seguinte forma: "pouco relevante" = 1 ; "moderadamente relevante" = 2; e "muito relevante" = 3. Já M refere-se ao fato do entrevistado ter indicado o fator i como mandatório.

\section{Discussão dos resultados}

Concluiu-se que a sinalização de valor de uma franquia (tendo a comunicação como fator mediador) é a dimensão que agrega o maior número de fatores que influenciam (influenciaram) a escolha de um (pretenso) franqueado no momento da escolha por uma franquia. Classificou-se tal dimensão de "dimensão de $1^{\text {a }}$ ordem". Essa dimensão foi subdividida em quatro dimensões de $2^{\mathrm{a}}$ ordem: (i) Task-related, (ii) Partner-related, (iii) Rede de franquias e (iv) Financeira (Quadro 1).

\begin{tabular}{|c|c|c|}
\hline Dimensão de $1^{\text {a }}$ Ordem & Dimensão de $2^{\mathrm{a}}$ Ordem & Dimensão de $3^{\mathrm{a}}$ Ordem \\
\hline 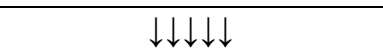 & $\downarrow \downarrow \downarrow \downarrow \downarrow$ & $\downarrow \downarrow \downarrow \downarrow \downarrow$ \\
\hline \multirow{7}{*}{$\begin{array}{l}\text { Sinalização de Valor } \\
\text { (Comunicação como } \\
\text { fator mediador) }\end{array}$} & \multirow{3}{*}{ Task-Related } & Suporte do Franqueador \\
\hline & & Marca \\
\hline & & Produtos \\
\hline & & Confiança no Franqueador \\
\hline & Partner-Related & $\begin{array}{l}\text { Outras características desejáveis do } \\
\text { franqueador }\end{array}$ \\
\hline & Rede de franquias & Qualidade/características da rede \\
\hline & Financeira & Disclosure Financeiro \\
\hline
\end{tabular}

\section{Quadro 1 - Dimensões agregadoras dos fatores que afetam a escolha por uma franquia}

Fonte: dados da pesquisa.

REUNA, Belo Horizonte - MG, Brasil, v.24, n.2, p.44-66, Abr. - Jun. 2019 - ISSN 2179-8834 
A dimensão Task-related (que, como foi visto, é de $2^{\text {a }}$ ordem) possui três dimensões de $3^{\underline{a}}$ ordem: (i) Suporte do franqueador, (ii) Marca e (iii) Produtos. Já a dimensão Partner-related subdivide-se nas seguintes dimensões, também de $3^{\text {a }}$ ordem: (i) Confiança no franqueador e (ii) Outras características desejáveis do franqueador. Já as duas últimas dimensões de $2^{a}$ ordem, a rede de franquias e a financeira possuem, cada uma delas, apenas uma única dimensão de $3^{\text {a }}$ ordem: para a primeira tem-se (i) Qualidade/Características da rede de franquias; já para a segunda, tem-se (ii) Disclosure financeiro.

O nível de agregação mais baixo é, naturalmente, os próprios fatores que influenciam (influenciaram) a escolha por uma franquia. Depois de eliminadas as redundâncias, gerou-se um total de 36 fatores que balizam a escolha de franquias, doravante designados apenas por "fatores". Destes 36 fatores, 32 foram extraídos da literatura, ao passo que os outros 4 foram posteriormente incluídos no estudo por terem sidos apontados nas entrevistas pelos próprios (pretensos) franqueados. Assim, os fatores representam a $4^{\text {a }}$ dimensão (ou dimensão de $4^{\text {a }}$ ordem). As subdivisões da dimensão de $3^{\underline{a}}$ ordem que originaram os fatores da dimensão de $4^{\underline{a}}$ ordem estão apresentadas no Gráfico 1.

O Gráfico 1 apresenta os resultados em termos de grau de importância para cada fator. A opinião dos respondentes foi capturada em uma escala que variou de 1 a 3, sendo que 1 corresponde a um grau de importância "Pouco Relevante", 2 corresponde a um grau de importância "Moderadamente Relevante" e, por fim, 3 corresponde a um grau de importância "Muito Relevante". Na última coluna da tabela, fez-se uma média do grau de importância informado por todos os respondentes. A escala desta última coluna varia de 0 a 1 , sendo que 0 seria um fator com pouca relevância, ao passo que 1 seria um fator de relevância absoluta. As células com a cor de fundo cinza muito escuro indicam um grau de importância acima de 0,90. Já as de fundo cinza escuro indicam um grau de importância entre 0,80 a 0,89. Em seguida, as de fundo cinza claro indicam um grau de importância entre 0,70 a 0,79 . Por fim, as de fundo cinza muito claro indicam um grau de importância entre 0 e 0,69.

No Gráfico 2, os resultados apresentados levaram em consideração o caráter mandatório de cada fator. A letra $M$, quando presente, indica que tal fator é mandatório, se não estiver em um bom nível, a franquia não será escolhida. Já quando o campo está em branco, tal fator não é mandatório (sendo, no caso, compensatório, pode estar em um nível inferior, se for compensado por outros.). A última coluna indica a frequência de citações pelos respondentes. A escala varia de 0 a 1 , sendo que 0 indica que nenhum respondente taxou de mandatório 0 respectivo fator, ao passo que 1 corresponde ao fator onde todos os respondentes 0 taxaram de mandatório.

A dimensão "suporte do franqueador" teve cinco fatores extraídos da literatura e um sexto extraído das próprias entrevistas com os franqueados, que foi adicionado posteriormente. Os fatores "bons serviços de operação ofertados pelo franqueador", "boa gestão da cadeia de suprimento", "treinamentos inicial e posteriores" e "fiel cumprimento do contrato e demais regras" tiveram grau de importância dentro do range máximo, ou seja, entre 0,90 e 1,00. Sendo esse último fator, justamente o fator extraído das entrevistas de campo, conforme mencionado anteriormente. Já os fatores "bons serviços de marketing nas fases pré e pós abertura de franquias" e "nível de controle adequado" foram considerados dentro da faixa de 0,80 a 0,89, 
apresentando um grau de importância que também é considerado relevante. Dentro dessa dimensão ("suporte do franqueador"), constatou-se forte correlação entre o grau de importância e o número de citações como de caráter mandatório, onde os fatores de maior grau de importância foram também os mais citados como mandatórios.

\section{Gráfico 1 - A importância dos atributos que influenciam a escolha de franquias}

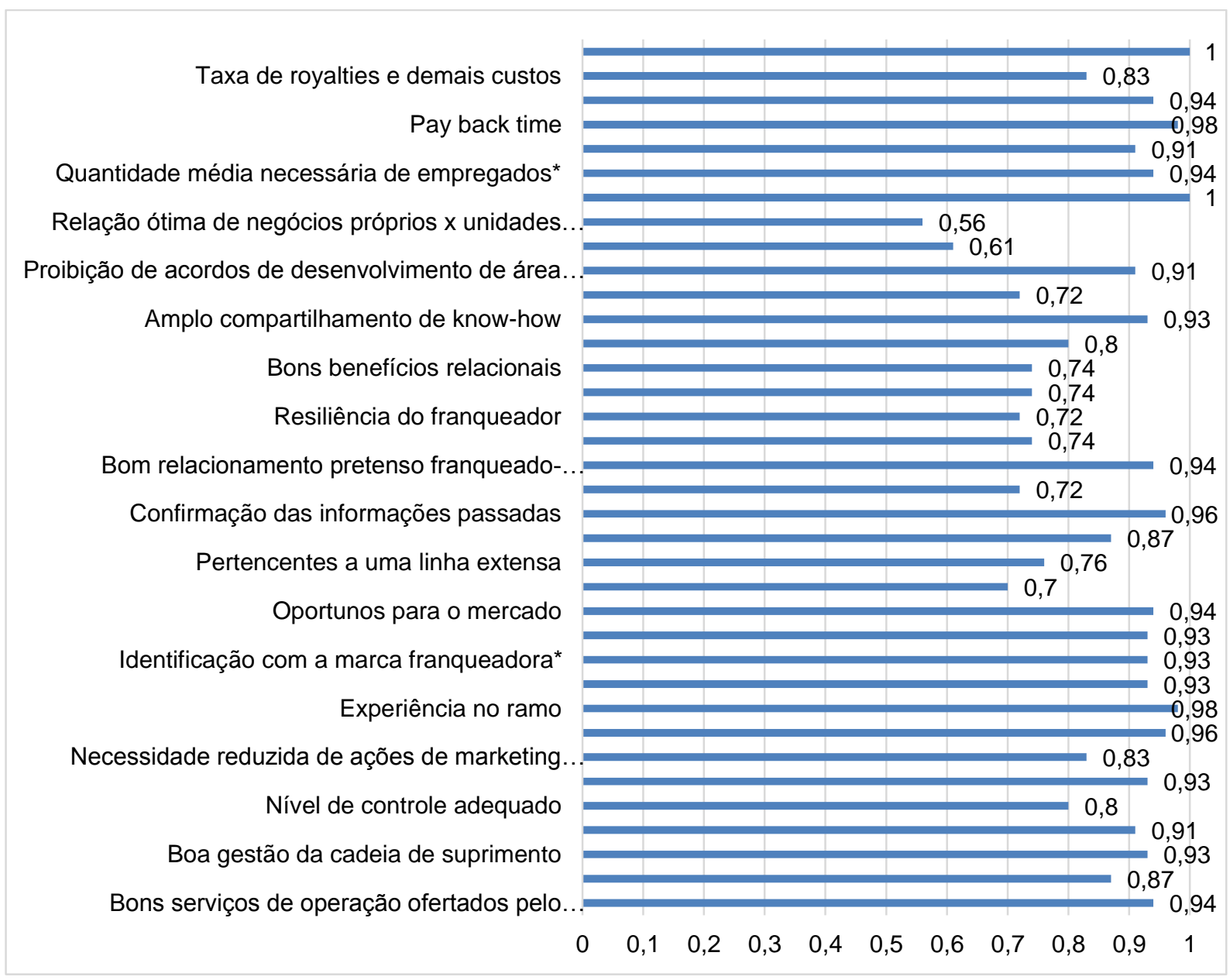

Fonte: Dados da pesquisa.

Na dimensão "marca", dos cinco fatores analisados, quatro tiveram pontuação dentro do range máximo, que foram: "base de clientes estabelecida", "experiência no ramo", "maturidade da franquia" e "identificação com a marca franqueadora" (esse último, o único fator dessa dimensão extraído da entrevista). Apenas o fator "necessidade reduzida de ações de marketing próprias" não ficou compreendido nesse range máximo, mas ainda assim ficou dentro do segundo range mais elevado. Embora a presente dimensão apresente em média grau de importância maior que a dimensão anterior ("suporte do franqueador"), percebeu-se que o número de citações como de caráter mandatório foi um pouco menor. Assim, observa-se que a 
"marca" foi considerada mais importante que o "suporte do franqueador", embora menos mandatória.

$\mathrm{Na}$ dimensão "produtos", os fatores "boa qualidade" e "oportunos para o mercado" apresentaram alto grau de importância, bem como foram citados, na grande maioria das vezes, como mandatórios. Isso significa que o perfil do (pretenso) franqueado da cidade Porto Alegre e região metropolitana não tem propensão a trabalhar com produtos de baixa qualidade e/ou inoportunos para 0 mercado. O mesmo não aconteceu com os fatores "inovativos" e "pertencentes a uma linha extensa". Os resultados de tais fatores induziram ao raciocínio de que o (pretenso) franqueado em análise tem um viés um pouco mais conservador em lidar com produtos inovativos, ao mesmo tempo que não quer se preocupar em lidar com um mix diversificado de produtos. Por fim, o fator "conhecimento prévio do produto", fator este que foi extraído das entrevistas (diferentes dos demais dessa dimensão), possui uma classificação intermediária. Tal fator foi considerado menos importante e mandatório que os dois primeiros dessa dimensão, ao passo que se revelou mais importante/relevante e mandatório que os dois fatores posteriormente citados. A inserção desse fator na atual dimensão foi conveniente, afinal, os resultados mostraram que o (pretenso) franqueado portoalegrense não tem propensão a se "aventurar" trabalhando com produtos menos conhecidos. Tal afirmação corrobora a tese conservadora anteriormente descrita.

A quarta dimensão analisada foi "confiança no franqueador". Merece destaque o fator "confirmação das informações passadas". À exceção do entrevistado de número 14, todos os outros entrevistados pontuaram tal fator como importante em seu mais alto grau, além de o terem citado também como mandatório. Em uma análise estatística, o resultado do entrevistado de número 14 seria certamente classificado como um outlier por apresentar pontuações discrepantes do resto da amostra. Isso significa dizer que o (prestenso) franqueado portoalegrense atribui grande valor para a confirmação das informações prestadas pelo franqueador. Da mesma forma, o (pretenso) franqueado da capital do Rio Grande do Sul valoriza um bom relacionamento com o franqueador (vide cotação do Fator 19 nas tabelas 1 e 2). Apesar de possuir um grau de importância de 0,72, a "boa gestão de conflitos" apresentou-se com um viés não mandatório $(0,22)$, sugerindo que o (pretenso) franqueado da região em questão pode ser considerado mais suscetível a conflitos que a média, sendo que tal característica não é mal interpretada pelas partes. Encerrando-se a análise da presente dimensão, o fator "confiança já estabelecida com os franqueados da rede" mostra que um pretenso franqueado, ao aderir a uma franquia, tende a analisar, por exemplo, como é o relacionamento entre os demais franqueados da rede e o franqueador. 
Gráfico 2 - Perfil mandatório de atributos que influenciam a escolha de franquias

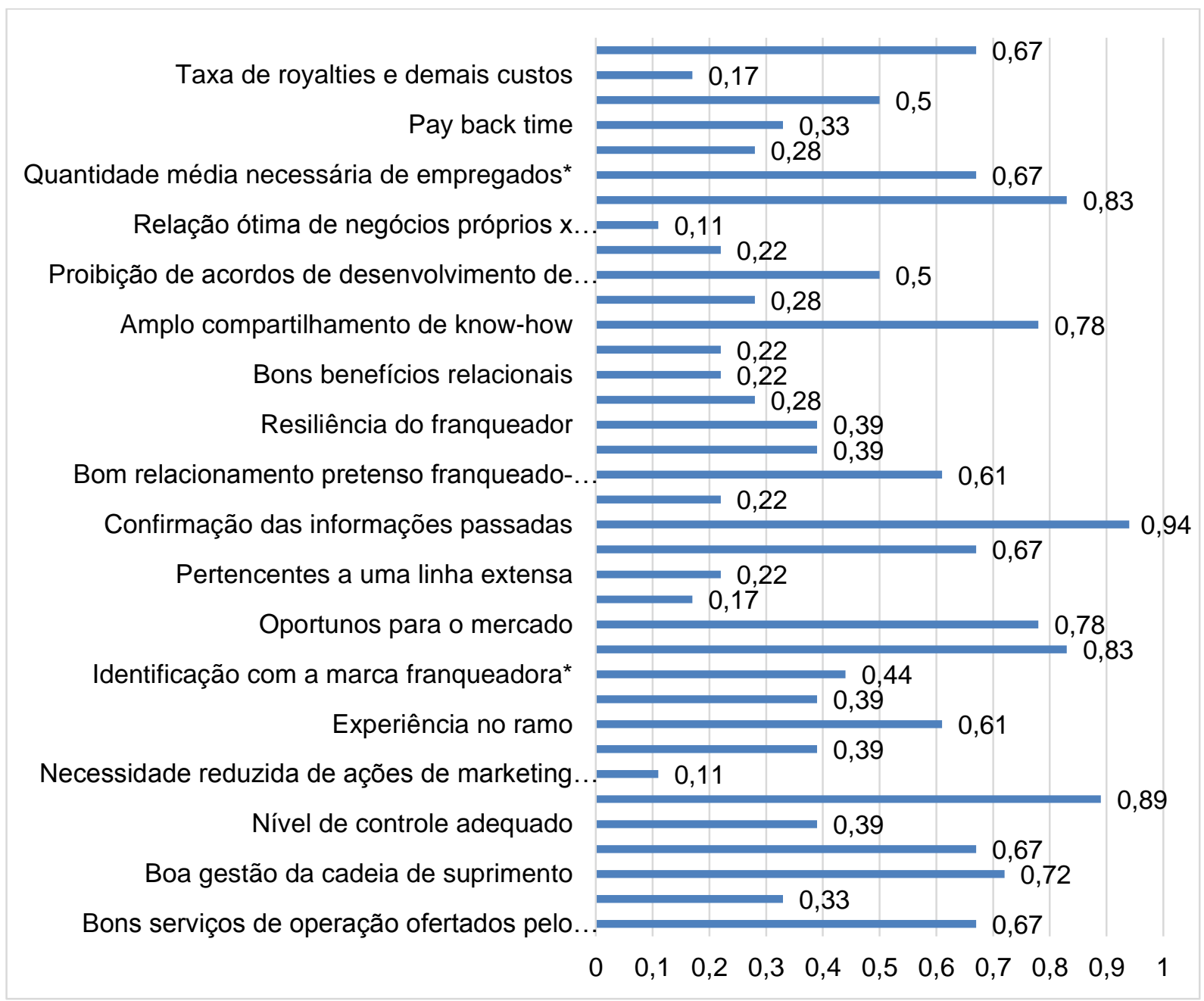

Fonte: Dados da pesquisa.

Na dimensão 5, "outras características do franqueador", procurou-se descobrir quais outras características do franqueador, exceto a característica confiança, teriam força na escolha de um (pretenso) franqueado por uma dada franquia. Os resultados mostraram que os fatores "resiliência do franqueador", "política de seleção que valoriza o perfil do franqueado", "bons benefícios relacionais" e "custos relacionais justos" ficaram com notas de importância entre 0,72 e 0,80, em uma escala que varia de 0,00 a 1,00. Embora bem cotadas nesse quesito, ao analisar-se o número de citações desses fatores como mandatórios, os resultados foram aquém, com pontuações entre 0,22 e 0,39. Essa dimensão teve um fator com resultados destoantes dos demais, trata-se do fator "amplo compartilhamento de know-how". Pode-se dizer que o franqueador que se empenha em compartilhar o know-how da franquia com seu pretenso franqueado tem mais chances de ser bem visto, bem como, na maioria dos casos, ser decisivo na adesão do pretenso franqueado por uma franquia. 
Na dimensão 6, "característica da rede", o fator "restrições de propriedade passiva" recebeu uma pontuação elevada no quesito relevância/importância, embora não tanto na parte mandatória. Isso revela que o pretenso franqueado indica certa preocupação em saber o quanto de sua propriedade será em sua maioria ativa ou passiva, mesmo que esse fator seja majoritariamente compensatório. Já o fator "proibição de acordos de desenvolvimento de área" é tido como muito importante na escolha por uma franquia pelos (pretensos) franqueados da capital do estado do Rio Grande do Sul. Tal público provavelmente não aderiria a uma franquia se pudesse ter, por exemplo, vários concorrentes próximos. O fator "permissão de subfranqueamento" é um instituto ainda não-legalizado no Brasil, onde, em um mesmo polo, tem-se o franqueado que é, ao mesmo tempo, franqueador. O citado fator não teve grande representatividade assertiva nas respostas dos entrevistados, tanto em nível de importância quanto em nível de mandatório. Mesmo assim, julgouse oportuno contemplá-lo, uma vez que a literatura norteamericana o cita. O fator "relação ótima negócios próprios versus unidades franqueadas" indica o quanto uma empresa é capilarizada por estabelecimentos próprios versus estabelecimentos franqueados. Dos 36 fatores analisados, é o fator que possuiu a menor pontuação em termos de importância na escolha por uma franquia. Da mesma forma, dos 18 entrevistados, apenas dois deles apontaram tal fator como mandatório durante a escolha, o que corresponde a cerca de 11\%. Os últimos dois fatores dessa dimensão apresentados, quais sejam, "território de boa localização onde situa-se a franquia" e "quantidade média necessária de empregados" ficaram pontuados no range máximo no quesito relevância/importância, o que significa que o (pretenso) franqueado tem uma preocupação acima da média para que tais fatores estejam sob sua gerência na hora da escolha por uma franquia. Uma observação se faz necessária ao fator "quantidade média necessária de empregados": Tal fator foi extraído das entrevistas realizadas.

A $7^{\text {a }}$ dimensão foi denominada de "disclosure financeiro". A abertura pelo franqueador de aspectos financeiros é muito bem vista pelo franqueado. Assim, dos cinco fatores pertencentes a essa dimensão ("investimento inicial", "pay back time", "risco", "taxa de royalites" e "rentabilidade"), apenas o fator taxa de royalties não está compreendida na faixa máxima de pontuação $(0,90$ e 1,00$)$ em termo de relevância/importância. Mesmo assim alcançou uma nota relativamente elevada $(0,83)$. Nota-se que ao fator "rentabilidade" foi atribuída nota máxima, 1,00, significando que todos os entrevistados indicaram ser muito relevante esse fator. Apesar de ser a dimensão mais pontuada em termos de importância, o mesmo não se confirmou no número de citações como sendo de caráter mandatório. A leitura que se faz é que, embora importantíssimo a ciência dos aspectos financeiros pelos (pretensos) franqueados, eles são, em sua maioria, negociáveis, principalmente uns com os outros.

O Quadro 2 resume, para cada dimensão, os fatores mais importantes / mandatórios e aqueles menos importantes / compensatórios. 
Quadro 2 - Resumo dos fatores que balizam a escolha de franquias

\begin{tabular}{|c|c|c|}
\hline DIMENSÕES & CLASSIFICAÇÃO & FATORES \\
\hline \multirow{6}{*}{ 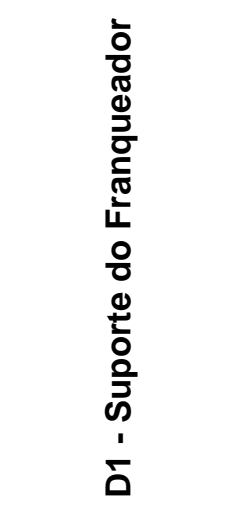 } & \multirow{4}{*}{$\begin{array}{l}\text { Mais importantes/ } \\
\text { mandatórios }\end{array}$} & Bons serviços de operação ofertados pelo franqueador \\
\hline & & Boa gestão da cadeia de suprimento \\
\hline & & Treinamentos inicial e posteriores \\
\hline & & Fiel cumprimento do contrato e demais regras estabelecidas* \\
\hline & \multirow{2}{*}{\begin{tabular}{|l} 
Menos \\
importantes/ \\
compensatórios
\end{tabular}} & Bons serviços de marketing nas fases pré e pós abertura \\
\hline & & Nível de controle adequado \\
\hline \multirow{5}{*}{ 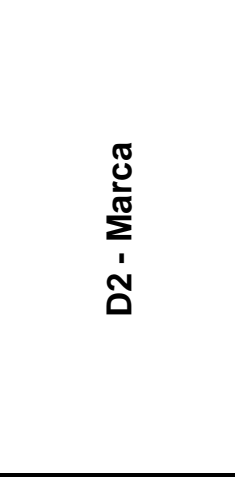 } & \multirow{4}{*}{$\begin{array}{l}\text { Mais importantes/ } \\
\text { mandatórios }\end{array}$} & Base de clientes estabelecida \\
\hline & & Experiência no ramo \\
\hline & & Maturidade da franquia \\
\hline & & Identificação com a marca franqueadora* \\
\hline & $\begin{array}{l}\text { Menos } \\
\text { importantes/ } \\
\text { compensatórios } \\
\end{array}$ & Necessidade reduzida de ações de marketing próprias \\
\hline \multirow{5}{*}{ 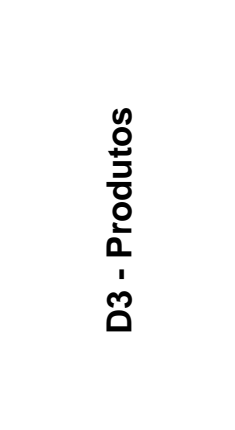 } & \multirow{3}{*}{$\begin{array}{l}\text { Mais importantes/ } \\
\text { mandatórios }\end{array}$} & Boa qualidade \\
\hline & & Oportunos para o mercado \\
\hline & & Conhecimento prévio do produto* \\
\hline & \multirow{2}{*}{$\begin{array}{l}\text { Menos } \\
\text { importantes/ } \\
\text { compensatórios }\end{array}$} & Inovativos \\
\hline & & Pertencentes a uma linha extensa \\
\hline \multirow{3}{*}{ 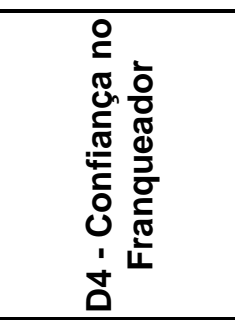 } & \multirow{2}{*}{$\begin{array}{l}\text { Mais importantes/ } \\
\text { mandatórios }\end{array}$} & Confirmação das informações passadas \\
\hline & & Bom relacionamento pretenso franqueado-franqueador \\
\hline & $\begin{array}{l}\text { Menos } \\
\text { importantes/ } \\
\text { compensatórios }\end{array}$ & Boa gestão de conflitos \\
\hline
\end{tabular}

Continua

REUNA, Belo Horizonte - MG, Brasil, v.24, n.2, p.44-66, Abr. - Jun. 2019 - ISSN 2179-8834 
Quadro 2 - Resumo dos fatores que balizam a escolha de franquias (continuação)

\begin{tabular}{|c|c|c|}
\hline DIMENSÕES & CLASSIFICAÇÃO & FATORES \\
\hline \multirow{5}{*}{ 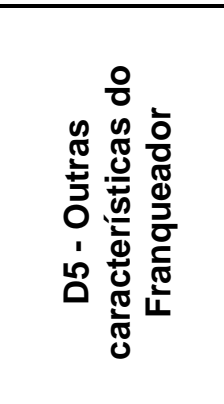 } & $\begin{array}{l}\text { Mais importantes/ } \\
\text { mandatórios }\end{array}$ & Amplo compartilhamento de know-how \\
\hline & \multirow{4}{*}{$\begin{array}{l}\text { Menos } \\
\text { importantes/ } \\
\text { compensatórios }\end{array}$} & Resiliência do franqueador \\
\hline & & Política de seleção que valorize o perfil do franqueado \\
\hline & & Bons benefícios relacionais \\
\hline & & Custos relacionais justos \\
\hline \multirow{6}{*}{ 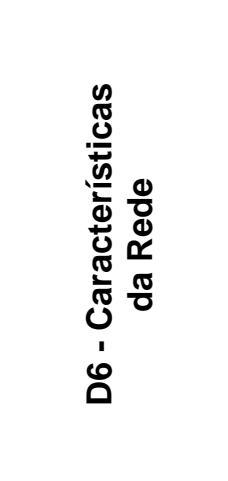 } & \multirow{3}{*}{$\begin{array}{l}\text { Mais importantes/ } \\
\text { mandatórios }\end{array}$} & Proibição de acordos de desenvolvimento de área (desejável) \\
\hline & & Território de boa localização onde situa-se a franquia \\
\hline & & Quantidade média necessária de empregados* \\
\hline & \multirow{3}{*}{$\begin{array}{l}\text { Menos } \\
\text { importantes/ } \\
\text { compensatórios }\end{array}$} & Restrições de propriedade passiva (desejável) - Controle? \\
\hline & & Permissão de subfranqueamento (desejável) ${ }^{* *}$ \\
\hline & & Relação ótima de negócios próprios $x$ unidades franqueadas \\
\hline \multirow{5}{*}{ 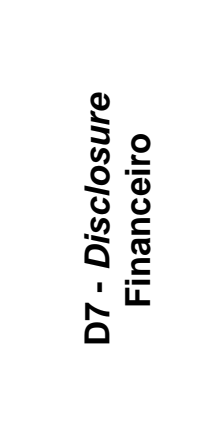 } & \multirow{4}{*}{$\begin{array}{l}\text { Mais importantes/ } \\
\text { mandatórios }\end{array}$} & Investimento inicial \\
\hline & & Pay back time \\
\hline & & Risco \\
\hline & & Rentabilidade \\
\hline & $\begin{array}{l}\text { Menos } \\
\text { importantes/ } \\
\text { compensatórios }\end{array}$ & Taxa de royalties e demais custos \\
\hline
\end{tabular}

Fonte: Dados da pesquisa.

\section{Considerações finais}

Este estudo investigou os critérios utilizados por potenciais franqueados na escolha por uma franquia em detrimento de outra(s).

Para o alcance desse objetivo, primeiramente foi feita uma revisão da literatura, que foi dividida em dois passos, segundo os seguintes subtítulos: (i) "Franquias - visão geral e contexto prático" e (ii) "critérios que balizam a escolha de franquias". Tal revisão de literatura permitiu extrair a primeira lista de critérios balizadores da escolha de franquias. Em seguida, foi-se a campo para entrevistar (pretensos) franqueados com a intenção de validar tais fatores. Nesse momento, procurou-se colher dos entrevistados outros fatores balizadores, que a revisão da literatura não contemplou. Baseado nessas duas fontes de informação, foi criada 
uma estrutura com trinta e seis fatores, sendo que trinta e dois deles foram extraídos da literatura, enquanto outros quatro foram capturados durante as entrevistas. Os entrevistados responderam pontuando o grau de importância de cada fator elencado, bem como esclarecendo sobre o caráter mandatório ou compensatório do respectivo fator.

O método proposto abrangeu entrevistados com conhecimento dos segmentos de "alimentação", "vestuário", "automotivo", "serviços" e "educação/entretenimento". A praça escolhida para entrevistar os (pretensos) franqueados foi Porto Alegre e região metropolitana.

Os resultados alcançados não se limitaram somente na definição dos trinta e seis fatores balizadores na escolha de franquias. Mais do que isso, foi feita uma estrutura dividida em quatro ordens de dimensões, onde os fatores balizadores foram classificados. A ordem de dimensão mais abrangente foi "sinalização de valor" tendo "comunicação" como fator mediador.

Os principais usuários dos resultados desta pesquisa são franqueadores em geral, uma vez que poderão posicionar melhor suas franquias, entendendo o processo de escolha dos (pretensos) franqueados. Em seguida, os resultados da pesquisa também são importantes aos franqueados, porque conhecendo a lista de fatores e sua estrutura poderão situar-se melhor em um processo de escolha por uma franquia. Além disso, evitarão de deixar de lado alguns fatores importantes e/ou mandatórios.

O presente trabalho incentiva novos estudos que poderão ser desenvolvidos posteriormente, principalmente focados no tratamento das limitações do mesmo. Tais estudos poderiam contemplar, por exemplo, outras praças, maior número de entrevistados, outros segmentos. Outra sugestão seria o desenvolvimento de uma estrutura para expressar financeiramente o impacto dos fatores balizadores.

Como sugestão para pesquisas futuras deve-se pensar em:

(i) Fazer uma pesquisa quantitativa com amostra maior utilizando a Análise Fatorial para validar estatisticamente as dimensões encontradas; (ii) Ampliar a amostra para outros mercados brasileiros e internacionais. 


\section{Apêndice - Modelo de questionário adotado na segunda etapa da pesquisa}

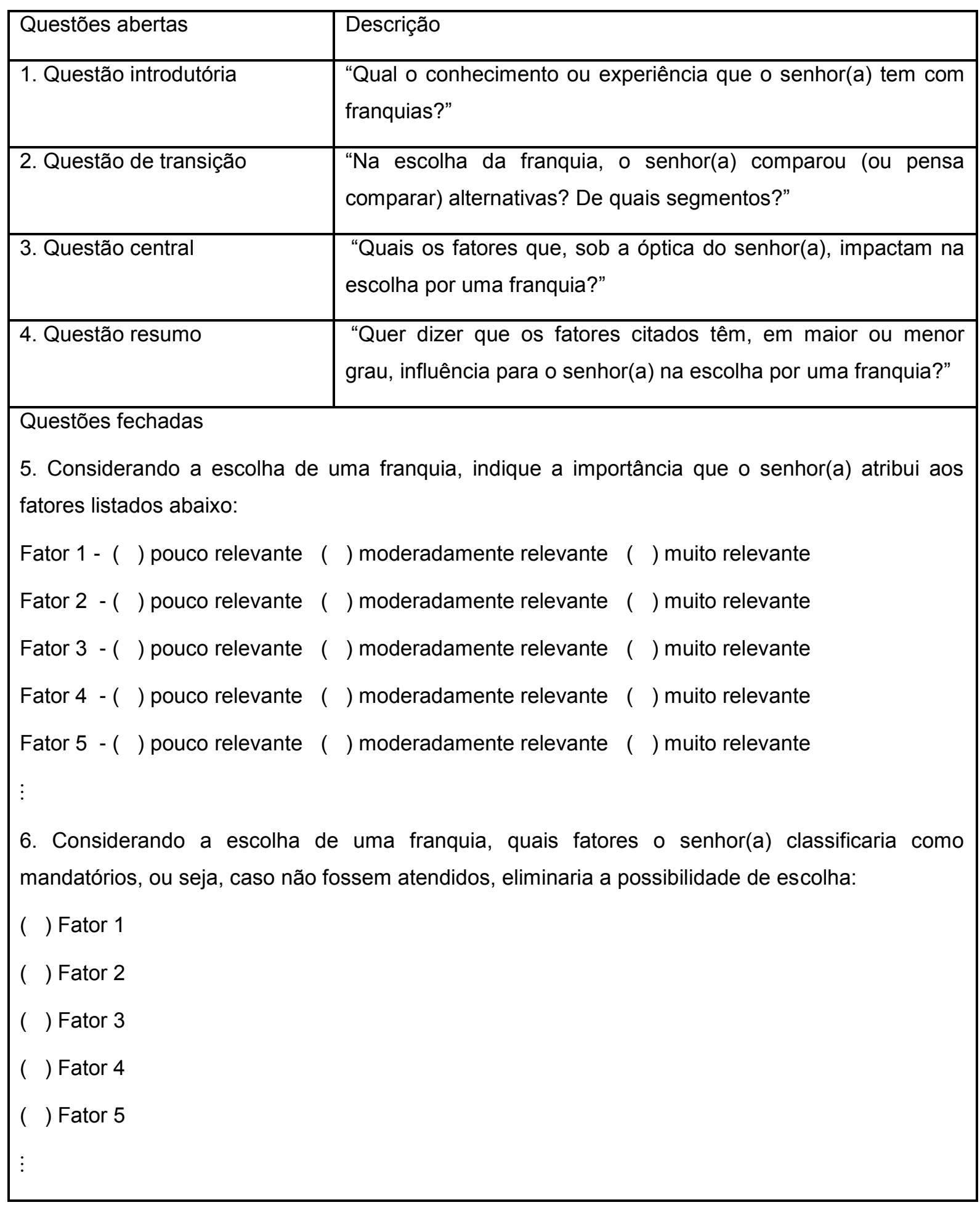

RELUNA, Belo Horizonte - MG, Brasil, v.24, n.2, p.44-66, Abr. - Jun. 2019 - ISSN 2179-8834 


\section{Referências}

ALTINAY, L.; BROOKES, M.; AKTAS, G. Selecting franchise partners: Tourism franchisee approaches, processes and criteria. Tourism Management, v. 37, p. 176185, 2013.

ALTINAY, L.; BROOKES, M.; MADANOGLU, M.; AKTAS, G. Franchisees' trust in and satisfaction with franchise partnerships. Journal of Business Research, v. 67, n. 5, p. 722-728, 2014.

ANWAR, S. Franchising: category issues, changing dynamics and competitiveness. International Journal of Commerce and Management, v. 21, n.3, p. 241-255, 2011.

ASSOCIAÇÃO BRASILEIRA DE FRANCHISING. ABF - Associação Brasileira de Franchising. Disponível em: <www.abf.com.br>. Acesso em: 21 jan. 2016.

BANCO CENTRAL DO BRASIL. Focus Relatório de Mercado. 2015. http:/www.bcb.gov.br/pec/GCl/PORT/readout/R20151231.pdf. Acesso em: 21 jan. 2016.

BENNETT, J. A year of growth, new rules and experimentation. The Wall Street Journal, november 6, p. D7, 2008.

BOYATZIS, R. E. Transforming qualitative information: Thematic analysis and code development. Thousand Oaks, CA: Sage, 1998.

BRASIL. Lei n. 8.955 de 15 de dezembro de 1994. Dispõe sobre o contrato de franquia empresarial (franchising) e dá outras providências. Disponível em: <http://www.planalto.gov.br/ccivil_03/Leis/L8955.htm>. Acesso em: 21 jan. 2016.

BRICKLEY, J. A.; DARK, F. H. The choice of organizational form: the case of franchising. Journal of Financial Economics, v.18, n.4, p. 401-420, 1987.

BROOKES, M.; ALTINAY, L. Franchise partner selection: perspectives of franchisors and franchisees. Journal of Services Marketing, v. 25, n. 5, p. 336-348, 2011.

CAMPBELL, D.; DATAR, S. M.; SANDINO, T. Organizational design and control across multiple markets: the case of franchising in the convenience store industry. The Accounting Review, v.84, n.6, p. 1749-1779, 2009.

CHAN, P. S.; JUSTIS, R. T. Franchising in the EC: 1992 and beyond. Journal of Small Business Management, v.30, January, p. 83-88, 1992.

CHIEN, S.; Franchisor resources, spousal resources, entrepreneurial orientation, and performance in a cople-owned franchise outlet. Management Decision, v. 52, n.5, p. 916-933, 2014.

DANT, R. P.; KAUFMANN, P. J.; PASWAN, A. K. Ownership redirection in franchised channels. Journal of Public Policy and Marketing, v.11, Spring, p. 33-34, 1992.

DANT, R.P.; WEAVEN, S.; BAKER, B. Influence of personality traits on perceived relationship quality within a franchisee-franchisor context. European Journal of Marketing, v. 47, n.12, p. 279-302, 2013. 
DAVIDOVITSCH, L.; CALDAS, L.F.; DA SILVA, J.F. Estruturação das redes de fast food: um estudo empírico sobre os antecedentes do franchising e suas implicações sobre o desempenho das firmas. Revista de Administração-RAUSP, v.44, n.4, p. 299-312, 2009.

GRACE, A.; FRAZER, L.; WEAVEN, S.; DANT. R. Building franchisee trust in their franchisor: insights from the franchise sector. Qualitative Market Research: An International Journal, v. 19, n.1, p. 65-83, 2016.

GROVES, R. M.; FOWLER, F. J.; COUPER, M. P.; LEPKOWSKI, J. M.; SINGER, E. \& T., R. Survey methodology. Hoboken, NJ: John Wiley \& Sons, 2004.

HODJE, C.; OPPEWAL, H.; TERAWATANAVONG, C. Determinants of franchise conversion: a franchisee perspective. European Journal of Marketing, v.7, n.10, p. 1554-1575, 2013.

HUNT, S. D. The trend toward company-operated units in franchise chains. Journal of Retailing, v.49, n.2, p. 110-119, 1973.

LAFONTAINE, F. Agency theory and franchising: some empirical results. Rand Journal of Economics, v. 23, n. 2, p. 263-283, 1992.

LAL, R. Improving channel coordination through franchising. Market Science, v.9, n.4, p. 299-318, 1990.

LEE, Y.; KIM, S.; KIM, M.; LEE, F.; LIM, K. Relational bounding strategies in the franchise industry: the moderating role of duration of the relationship. Journal of Business \& Industrial Marketing, v. 30, n.7, p.830-841, 2015.

MELO, P.L. de R.; BORINI, F.M.; CUNHA, J.A.C. da. Microfranchising value perception and structural elements. Revista de Administração Contemporânea, v.18, n.3, p. 328-350, 2014.

MELO, P.L. DE R; BORINI, F. M.; OLIVEIRA JUNIOR, M.D.M.; PARENTE, R. C. International analysis of the countries where Brazilian franchise chains operate. Revista de Administração, v.50, n.1, p. 26-39, 2015.

NORTON, S. W. An empirical look at franchising as an organizational form. Journal of Business, v.61, n.2, p. 197-218, 1988.

NYADZAYO, M.W.; MATANDA, M.J.; EWING, M.T. The impact of franchisor support, brand commitment, brand citizenship behavior, and franchisee experience on franchisee-perceived brand image. Journal of Business Research, v.68, n.9, p. 1886-1894, 2015.

PALACIOS, L.; FUSTE, V.; MADANOGLU, M.; ALON, I. Franchising and value signaling. Journal of Services Marketing, v.28, n.2, p. 105-115, 2014.

PETERSON, A.; DANT, R. P. Perceived advantages of the franchise option from the franchisee perspective: empirical insight from a service franchise. Journal of Small Business Management, v.28, n.3, p. 46-61, 1990.

QUINN, B. Control and support in an international franchise network. International Marketing Review, V. 16, n. 4/5, p. 345-362, 1990.

SASHI, C. M.; KARUPPUR, D. Franchising in global markets: towards a conceptual framework. International Marketing Review, v.19, n.5, p.499-524, 2002. 
SHAIKH, A. Conceptualizing fairness in franchisor-franchisee relationship: Dimensions, definitions and preliminary construction of scale. Journal of Retailing and Consumer Services, v.28, p. 28-35, 2016.

SHANE, S. Making new franchise systems work. Strategic Management Journal, v.19, n.7, p. 697-707, 1998.

SZULANSKI, G.; JENSEN, R. J. Growing through copy: the negative consequence of innovation on franchise network growth. Research Policy, v.37, n.10, p. 1732-1741, 2008.

DE SALLES VANCE, P.; FÁVERO, L.P.L.; LUPPE, M.R. Franquia empresarial: um estudo das características do relacionamento entre franqueadores e franqueados no Brasil. Revista de Administração-RAUSP, v.43, n.1, p. 59-71, 2008.

WEAVEN, S.; GRACE, D.; FRAZER, L. The effect of pre-entry information on relational outcomes in franchising. European Journal of Marketing, v.48, n.1/2, p. 193-217, 2014.

WRIGHT, O.; WINZAR, H. Franchise system investment disclosure: signaling value to prospective franchisees. Asia Pacific Journal of Marketing and Logistics, v.26, n.3, p. 365-377, 2014.

WU, C.W. Antecedents of franchise strategy and performance. Journal of Business Research, v.68, n.7, p. 1581-1588, 2015. 